\title{
Are experimental economists prone to framing effects? A natural field experiment
}

\author{
Simon Gächter*, Henrik Orzen ${ }^{1}$, Elke Renner ${ }^{2}$, Chris Starmer ${ }^{3}$ \\ Centre for Decision Research and Experimental Economics, University of Nottingham, UK
}

\section{A R T I C L E I N F O}

\section{Article history:}

Received 15 April 2007

Received in revised form 11 October 2007

Accepted 28 November 2007

Available online 22 January 2009

\section{JEL classification:}

C93

D01

Keywords:

Framing

Field experiments

\begin{abstract}
A B S T R A C T
An extensive literature demonstrates the existence of framing effects in the laboratory and in questionnaire studies. This paper reports new evidence from a natural field experiment using a subject pool one might expect to be particularly resistant to such effects: experimental economists. We find that while the behaviour of junior experimental economists is affected by the description of the decision task they face, this is not the case for the more senior members of our subject pool.
\end{abstract}

(c) 2009 Elsevier B.V. All rights reserved.

\section{Introduction}

This paper reports a natural field experiment designed to test the principle of description invariance, that is, the presumption that an agent's choice from a feasible set of alternatives should be unaffected by any re-description of it that leaves all objective characteristics unchanged. While this principle has considerable normative appeal, there is evidence that it fails descriptively in simple laboratory settings; choices do depend on how a task is framed.

Most studies on framing effects (including ours) describe logically equivalent decision situations in either a positive or a negative light. ${ }^{4}$ The "Asian Disease Problem", due to Tversky and Kahneman (1981), is a well-known example. Describing a choice between medical programmes in terms of lives saved or lives lost led to dramatically different answers, although the problems were logically equivalent. Levin et al. (1998) provide an overview and classification of framing effects found in numerous laboratory and questionnaire studies, both in the context of individual decision making as well as in experimental games.

Our paper extends this literature by testing for the existence of a framing effect within a natural field experiment. In our experiment, the participants were junior and senior experimental scientists (mostly economists) who registered for the 2006

\footnotetext{
* Corresponding author at: University of Nottingham, School of Economics, Sir Clive Granger Building, University Park, Nottingham, NG7 2RD, United Kingdom Tel.: +44 11584 66132; fax: +44115951 4159.

E-mail addresses: simon.gaechter@nottingham.ac.uk(S. Gächter), henrik.orzen@nottingham.ac.uk (H. Orzen), elke.renner@nottingham.ac.uk

(E. Renner), chris.starmer@nottingham.ac.uk (C. Starmer).

1 Tel.: +44 11584 67847; fax: +44115951 4159 .

2 Tel.: +4411595 15399; fax: +441159514159.

3 Tel.: +441158466067; fax: +441159514159.

4 Not all studies of framing focus on the positive/negative contrast. For example, Frey and Meier (2004) use field data to investigate whether a change in the timing of a decision affects charitable giving.
} 
Table 1

Participants and decision frames.

\begin{tabular}{llll}
\hline & Type of participant & & \\
\cline { 2 - 4 } & Junior & Senior & 43 \\
Discount frame & 18 & 32 & 61 \\
Penalty frame & 27 & 59 & 75 \\
Total & 45 & 120 \\
\hline
\end{tabular}

Economic Science Association (ESA) meeting in Nottingham, UK. As part of the normal organizational process, all people who had submitted a paper received an email reminding them to register. The experimental framing manipulation concerned the fee for late registration. Half of the participants were told that there is a "penalty" of $\$ 50$ for registering after the first deadline. The other half of participants were told that there is a "discount" of $\$ 50$ for registering before the first deadline. If we observe different registration patterns for these groups, we have field evidence for a framing effect. ${ }^{5}$

A few methodological remarks on our experiment are in order. First, registering for a conference is part of the usual business of any scientist, and while doing so for ESA-Nottingham our 120 participants were not aware that they were taking part in an experiment. Our experiment therefore classifies as a "natural field experiment", to borrow the terminology of Harrison and List (2004). Second, the stakes were substantial and beyond those used in typical lab experiments. Third, if as an (experimental) economist you were sceptical about the relevance of framing effects, you ought to be especially persuaded by evidence from a natural field experiment using economists as subjects. So, are experimental economists prone to framing effects? Read on if you would like to know the answer.

\section{The experiment}

We conducted the experiment in the run-up to the 2006 ESA conference in Nottingham. After the submission deadline we sent an email to all prospective conference participants informing them about the acceptance of their paper and other organizational details. To investigate whether participants' decisions about when to pay the conference fee were independent of the description of the task, we randomly assigned them to one of two treatment groups. Both groups received in essence the same acceptance email - except for one sentence. ${ }^{6}$ In one version we framed the difference between early and late registration fee as a discount:

"We take this opportunity to remind you that the discounted conference fee for early registration is available until 10 July 2006."

In a second version we used a penalty frame:

"We take this opportunity to remind you that the conference fee will include a penalty for late registration after 10 July 2006."

As is usual for scientific conferences there were two types of registration fee: a regular fee for faculty and a reduced fee for PhD students. The early-registration fee was $\$ 195$ for faculty and $\$ 145$ for PhD students, and the late registration fee was $\$ 245$ for faculty and $\$ 195$ for PhD students. The difference in fees due to people's eligibility for the student reduction naturally divides our subjects into two subgroups, which we classify as "senior" and "junior" conference participants and which we will examine separately in our data analysis.

Registration for the conference took place through the ESA website, which recorded the dates of all payments and automatically switched to the late fee on July 11 th. The final number of experimental subjects (some withdrew their submissions) was 120 . Table 1 shows how junior and senior experimental economists were distributed between the two treatment groups. ${ }^{7}$

\section{Results}

Most of our subjects, 101 out of 120 (84\%), registered early ( $82 \%$ of the junior participants and $85 \%$ of the senior participants). There are many reasons why participants might register early rather than late, but we suspect a major reason is the difference in price. The predominance of early registrants in our sample is exactly what we would expect if incentives matter.

But does it make a difference whether early registration is described as an opportunity to avoid a penalty or as an opportunity to take advantage of a discount? We examine our data in two main steps. First, we report results of a simple

\footnotetext{
5 In the terminology of Levin et al. (1998) our experiment manipulates "goal framing". They list 27 studies on goal framing. Almost all of them are laboratory or questionnaire studies. A rare example of a field experiment investigating framing is Ganzach and Karsahi's (1995) study of credit card use.

6 The full text of the email is provided in the appendix.

7 The random assignment resulted in a slightly uneven distribution of junior and senior participants across treatments. Note that when we did the assignment we were unable to discriminate between these two groups since at the time we did not know who would be eligible for the reduced student fee.
} 
Table 2

Proportions of early registration by treatment and type of participant p-values from two-tailed Fisher exact tests.

\begin{tabular}{|c|c|c|c|}
\hline & Discount frame & Penalty frame & $p$-Value for difference \\
\hline Senior & $88 \%$ & $81 \%$ & 0.513 \\
\hline Junior & $67 \%$ & $93 \%$ & 0.045 \\
\hline Overall & $82 \%$ & $86 \%$ & 0.338 \\
\hline
\end{tabular}

Table 3

Determinants of registration behaviour ${ }^{\dagger}$.

\begin{tabular}{|c|c|c|}
\hline \multirow[t]{2}{*}{ Independent variables } & \multicolumn{2}{|c|}{ Dependent variable: probability of registering early } \\
\hline & Coefficients from probit regression & Marginal effects of changes in variables \\
\hline Constant & $1.351^{* * *}(0.3123)$ & \\
\hline \multicolumn{3}{|l|}{ Penalty } \\
\hline $0(1)=$ Discount (Penalty) frame & $-0.310(0.4411)$ & $-0.066(0.0946)$ \\
\hline \multicolumn{3}{|l|}{ Junior } \\
\hline $0(1)=$ Senior (Junior) & $-1.059^{* *}(0.4481)$ & $-0.259^{* *}(0.1188)$ \\
\hline Penalty $\times$ Junior & $1.559^{* *}(0.6388)$ & $0.212^{* *}(0.0598)$ \\
\hline \multicolumn{3}{|l|}{ NonEU } \\
\hline $0(1)=$ European (Non-European) institution & $-1.273^{* *}(0.5841)$ & $-0.391^{* *}(0.2092)$ \\
\hline Penalty $\times$ NonEU & $0.681(0.7567)$ & $0.104(0.0784)$ \\
\hline \multicolumn{3}{|l|}{ Female } \\
\hline $0(1)=$ Male (Female) & $0.443(0.4589)$ & $0.087(0.0809)$ \\
\hline Penalty $\times$ Female & $-0.376(0.6822)$ & $-0.093(0.1913)$ \\
\hline
\end{tabular}

$N=120$ Prob. $>\chi^{2}=0.0879$ Pseudo $R^{2}=0.1183$.

$\dagger$ Standard errors in parentheses.

${ }^{* *}$ Significance at the $5 \%$ level.

*** Significance at the $1 \%$ level.

nonparametric statistical analysis using the Fisher exact test. Second, we conduct a probit regression analysis to investigate whether including, and controlling for, additional explanatory variables confirms our findings from step one and/or adds any other insights on the behaviour of our subjects.

Table 2 provides details of our nonparametric analysis. As is evident from the bottom row, in the aggregate data there is no evidence of a framing effect. However, this disguises an interesting difference between the behaviour of junior and senior participants. When we disaggregate, although we still see no framing effect for senior participants, for junior researchers we do observe a substantial and statistically significant change in behaviour: one third in the discount group registered late, whereas in the penalty frame almost everybody registered early.

We have two potentially relevant pieces of background data on each conference attendee: their gender and the geographical location of their home institution. In our sample 68\% are male and $85 \%$ are from European institutions (almost all the others came from North American institutions). We included this information as explanatory variables in a probit regression. As seen in Table 2, the effect of the treatment variable on behaviour interacts with the subject type, so we also allow for interaction effects between treatment and subject characteristics in the regression.

The regression results are shown in Table 3, and they confirm and extend our earlier findings. The impact of the treatment variable on senior researchers is negligible. In contrast, being a junior participant in the discount treatment is associated with a large and significant drop in the probability of registering early, which is then reversed by a similarly sized increase for juniors in the penalty treatment. Taken together, these results suggest that the members of the penalty junior group and both senior groups all behave in a similar way, whereas the members of the discount junior group display an increased inclination to register late.

Gender has no significant effect on registration behaviour, and males and females do not respond differently to the treatment variation. A conference participant's home location, however, has a very strong effect on behaviour: non-European attendees are almost $40 \%$ more likely to register late. However, there is no evidence of a stronger framing effect among non-Europeans.

\section{Conclusion}

Our study has produced clear evidence of a framing effect in a natural field experiment. A question raised by our study is why that effect occurs for juniors but not seniors. A variety of possible differences between the characteristics of juniors and seniors might explain this. One such difference is that financing conference visits may be easier for faculty members than for PhD students. Notice that for this to account for our findings, one would have to argue that juniors are prone to the framing effect because they face, due to their tighter budget constraints, higher incentives than the seniors. However, if access 
to funding were indeed an important factor in determining behaviour, we would expect a generally increased inclination among juniors to register early, yet we do not observe this (overall, the proportion of early registrations is almost identical for juniors and seniors). Another possibly relevant difference is that seniors have more experience in making decisions related to conference attendance, and there is evidence to suggest that more experienced choosers are less prone to some decision anomalies (e.g. List, 2003). While these interpretations are speculative, our experiment does provide a clear and simple answer to the question it was designed to address. Are experimental economists prone to framing effects? On the basis of our data the answer is: juniors are and seniors are not.

\section{Acknowledgements}

We thank Martin Sefton, John List, Nikos Nikiforakis and two anonymous referees for very helpful comments.

\section{Appendix}

$$
\{\ldots\}=\text { Discount frame } \quad[\ldots]=\text { Penalty frame }
$$

Dear Sir or Madam,

Thank you for submitting your abstract to the Economic Science Association 2006 European Meeting. We are pleased to inform you that your paper has been accepted for inclusion in the programme.

Please register and pay through the ESA web page.

[We take this opportunity to remind you that the conference will include a penalty for late registration after 10 July 2006 .]

\{We take this opportunity to remind you that the discounted conference fee for early registration is available until 10 July 2006 .

To register please go to the ESA website (www.economicscience.org) and log in with your email address and password. If you haven't got an account yet, you have to sign up first (just follow the "log in" link on the ESA website). You can sign up for free without becoming a member of the Economic Science Association, and you do not have to be a member to attend the conference.

When you make your travel arrangements, keep in mind that the conference will begin with a reception on Thursday, 7 September, at 18:00 and end at 15:00 on Sunday, 10th September. For information about hotels and transportation please visit the Conference website www.nottingham.ac.uk/economics/cedex/ESA2006/index.html

We will publish the preliminary programme in the second half of July.

We look forward to welcoming you in Nottingham.

Best regards,

Local Organising Committee

ESA 2006 European Regional Meeting

\section{References}

Frey, B.S., Meier, S., 2004. Pro-social behavior in a natural setting. Journal of Economic Behavior and Organization 54, 65-88.

Ganzach, Y., Karsahi, N., 1995. Message framing and buying behavior: a field experiment. Journal of Business Research $32,11-17$.

Harrison, G.W., List, J.A., 2004. Field experiments. Journal of Economic Literature 42, 1009-1055.

Levin, I.P., Schneider, S.L., Gaeth, G.J., 1998. All frames are not created equal: a typology and critical analysis of framing effects. Organizational Behavior and Human Decision Processes 76, 149-188.

List, J.A., 2003. Does market experience eliminate anomalies? Quarterly Journal of Economics 118, 41-71.

Tversky, A., Kahneman, D., 1981. The framing of decisions and the psychology of choice. Science 211, 453-458. 